\title{
Desenvolvimento de elementos aerodinâmicos para veículos de competição BAJA - SAE
}

\author{
Development of aerodynamic elements of \\ competition vehicles type BAJA - SAE
}

\author{
Rodrigo Cézar Primon \\ Savazzi \\ Tecnólogo em Aeronáutica \\ Mestrando em Engenharia e \\ Gestão da Inovação, \\ Universidade Federal do ABC, \\ Santo André, Brasil.

\section{Crhistian Raffaelo Baldo} \\ Doutor em Engenharia \\ Mecânica \\ Docente do Centro de \\ Engenharia e Ciências Sociais \\ Aplicadas, Universidade \\ Federal do ABC, Santo André, \\ Brasil \\ christian.baldo@ufabc.edu.br

\section{Rovilson Mafalda} \\ Doutor em Engenharia Civil \\ Docente do Centro de \\ Engenharia e Ciências Sociais \\ Aplicadas, Universidade \\ Federal do ABC, Santo André, \\ Brasil \\ rovilson.mafalda@ufabc.edu.br
}

\section{RESUMO}

Neste artigo é apresentado o desenvolvimento de elementos aerodinâmicos para um veículo de competição tipo Baja SAE. A competição Baja SAE envolve instituições de ensino de todo Brasil, seus eventos já são tradicionais e envolvem uma grande quantidade de estudantes de diversas áreas de Engenharia. Em geral os projetos dos estudantes focam elementos essenciais nos carros como tração, suspensão, freios, porém se tem observado que elementos de aerodinâmica não têm despertado interesse das equipes. Buscando contribuir com o item de aerodinâmica descrito no regulamento da competição, este artigo aborda os pontos principais da aplicação de elementos aerodinâmicos em um protótipo Baja SAE típico. Espera-se com isso fomentar o interesse de estudantes para este domínio e prover um método de incremento de desempenho destes veículos.

Palavras-chave: Baja SAE, aerodinâmica, dinâmica dos fluidos.

\section{ABSTRACT:}

This article presents the development of aerodynamic elements for a Baja SAE type competition vehicle. The Baja SAE competition involves Universities from all regions of Brazil and those events are already traditional and involve a large number of students from various Engineering areas. In general, students' projects focus on essential elements in cars such as traction, suspension, brakes, but it has been observed that aerodynamics have not aroused the interest of the teams. In order to contribute to the aerodynamic of those vehicles, this article addresses the main points of the application of aerodynamic elements in a typical Baja SAE prototype. It is expected that this article can arise the interest of students about this field and provide a method to increase the performance of this class of vehicles.

Keywords: Baja SAE, aerodynamics, fluid dynamics. 


\section{INTRODUÇÃO}

A competição Baja SAE consiste em uma série de provas estáticas e dinâmicas que visam a replicar num ambiente competitivo os desafios encontrados no mundo real da engenharia. Durante a competição, voltada a estudantes de engenharia, as equipes participantes são desafiadas a projetar, construir e colocar à prova um monoposto para uso fora de estrada, que deve ser desenvolvido como um protótipo de um veículo a ser produzido em linha e colocado no mercado, que seja confiável, ergonômico, seguro e econômico, além de atrativo para o consumidor final. (SAE BRASIL, 2017a) A competição Baja SAE originou-se de outra prova, a "Recreational-Ecological-Vehicle (REV) Contest”, concebida pelo Dr. William R Shapton em 1973, e no Brasil a competição é realizada desde 1995, quando ocorreu a "I Competição SAE BRASIL de Mini Baja" disputada por sete equipes entre os dias 11 e 12 de fevereiro na pista Guido Caloi, no bairro de Ibirapuera em São Paulo. (SILVA, VIEIRA e TAVARES, 2016) Em 2016, na 22 a edição da competição brasileira, participaram alunos de 67 universidades, faculdades e instituições de ensino superior, compondo 74 equipes (SAE BRASIL, 2017b).

Conforme o regulamento da competição, a equipe campeã é aquela que obtém mais pontos em todas as provas combinadas. Buscando melhorar o desempenho do veículo Baja, descreve-se neste artigo um estudo sobre o desenvolvimento de elementos de aerodinâmica para melhorar o desempenho do veículo. Espera-se com isso fomentar o interesse de estudantes para este aspecto do projeto e tornar os veículos mais competitivos.

\section{DESENVOLVIMENTO}

O foco deste trabalho é propor um pacote aerodinâmico que possa ser aplicado por um Baja SAE típico sem modificar seu projeto nem interferir com o funcionamento de seus sistemas, ou seja, uma evolução dos projetos atuais e que seja facilmente implementado pela maioria das equipes participantes da competição. 0 pacote aerodinâmico proposto consiste em duas partes distintas: uma carenagem a ser aplicada sobre os pneus e uma carenagem traseira em forma de um defletor.

\subsection{Carenagem sob pneus}

A adoção de carenagens sobre os conjuntos roda/pneu tem inspiração nas aeronaves que possuem trens de pouso fixos, onde, para evitar o arrasto aerodinâmico, adota-se uma carenagem sobre os pneus. Apesar do acréscimo de peso, área frontal e complexidade, esse tipo de cobertura costuma trazer benefícios bastante expressivos, de forma que uma derivação deste conceito foi considerada neste trabalho.

O desenvolvimento da carenagem iniciou-se pela elaboração de um projeto básico, derivado diretamente de perfis aerodinâmicos conhecidos. $\mathrm{Na}$ 
sequência, esses perfis foram testados em um software para análise de dinâmica dos fluidos computacional (CFD - Computational Fluid Dynamics). 0 projeto foi elaborado utilizando-se o software SolidWorks versão 2016, desenvolvido e comercializado pela Dassault Systèmes. Como ponto de partida para o desenho da carenagem foram utilizados modelos de roda e pneu elaborados em softwares CAD e disponibilizados para uso através da internet, no site GRAB CAD (http://www.grabcad.com).

Os desenhos foram elaborados com base em perfis aerodinâmicos conhecidos, provenientes da base de dados do site Airfoil Tools (http://airfoiltools.com). Inicialmente, selecionaram-se perfis através de suas características básicas e também, em alguns casos, de uma análise dimensional prévia (Figura 1), gerando doze modelos distintos, mostrados na Figura 2.

Figura 1: Análise dimensional prévia de alguns dos perfis considerados. com as informações.

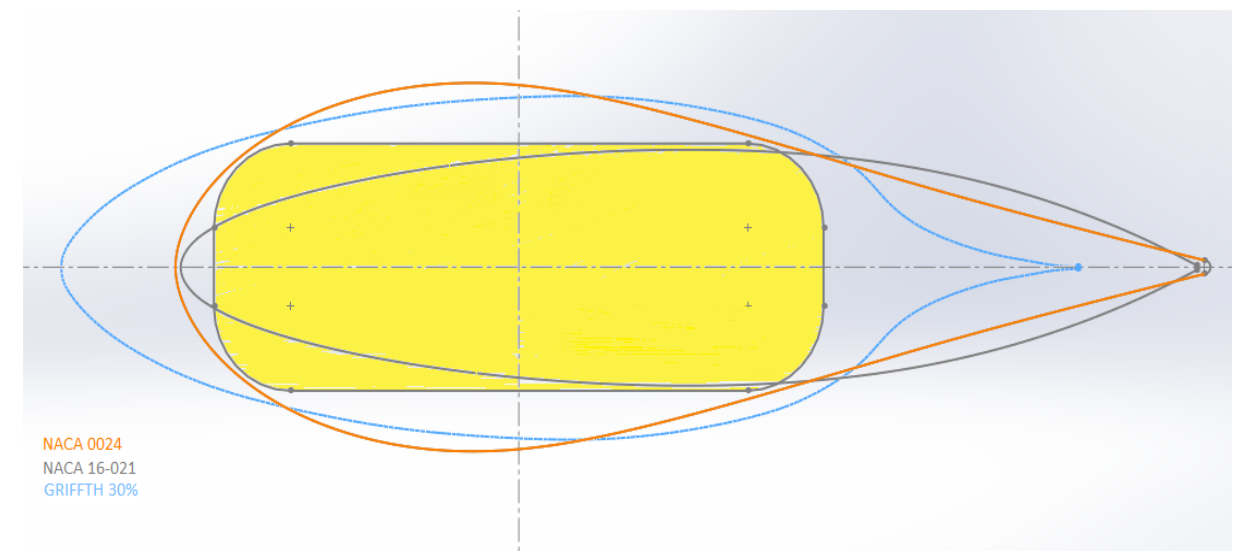

Fonte: Elaborada pelos autores.

Os perfis foram selecionados tendo como critério inicial os de maior espessura relativa, que é a razão entre a espessura máxima da seção de um aerofólio, medida perpendicularmente à corda, e o comprimento da corda (ASSOCIAÇÃO BRASILEIRA DE NORMAS TÉCNICAS, 2011), de modo a poder acomodar em seu interior o conjunto roda/pneu. A espessura relativa também não poderia variar muito na parte central que acomodaria o pneu, pois caso contrário resultaria em uma carenagem muito larga, aumentando consideravelmente a área frontal da carenagem e impactando negativamente no arrasto.

Os modelos básicos gerados foram então testados através do módulo de CFD FloXpress, integrado ao software SolidWorks. Para as análises, os modelos foram montados sobre um conjunto de roda e pneu. A Figura 3 ilustra o arranjo dos conjuntos testados. 
Figura 2: Alguns dos modelos de carenagem concebidos e testados.

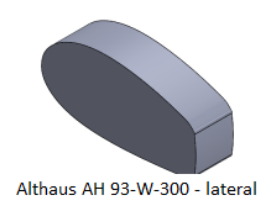

Althaus AH 93-W-300 - lateral

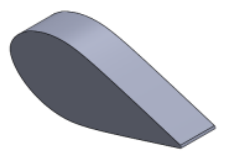

Eppler E 864 - lateral

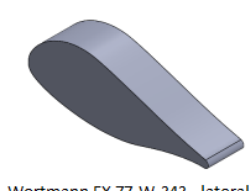

Wortmann FX 77-W-343 - lateral

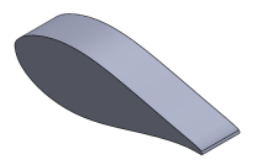

Althaus AH 94-W-301 - lateral

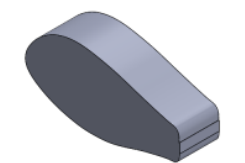

Wortmann FX 79-W-470A - lateral

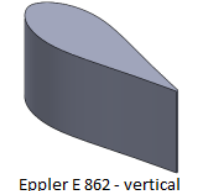

Eppler E 862 - vertic

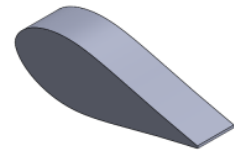

Eppler E 862 - lateral

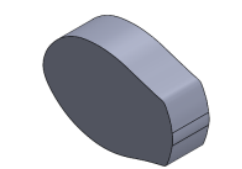

Wortmann FX 79-W-660A - lateral

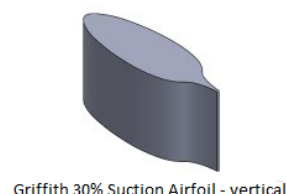

Griffith $30 \%$ Suction Airfoil - vertical

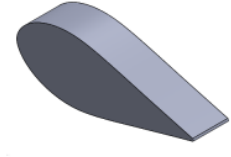

Eppler E 863 - lateral

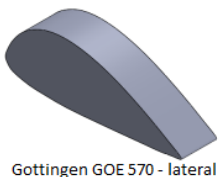

Fonte: Elaborada pelos autores.

Figura 3: Conjunto roda/pneu e exemplos de montagens utilizadas nas análises.

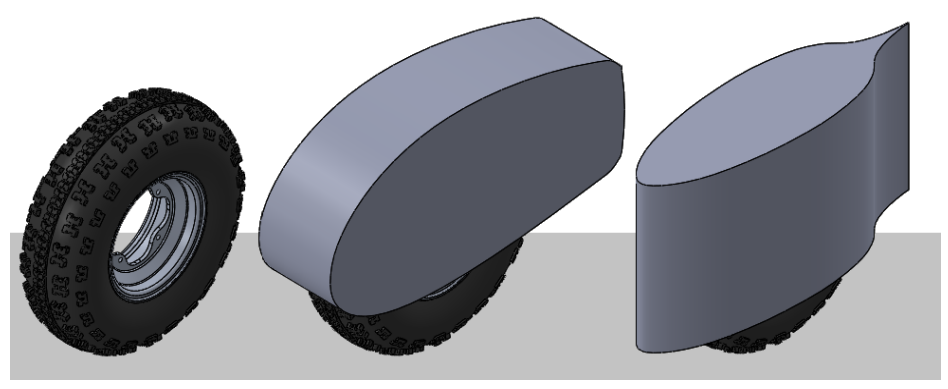

Fonte: Elaborada pelos autores.

Os conjuntos foram montados sobre uma superfície plana e lisa de maneira a simular a interação com o solo. De acordo com os resultados publicados da competição Baja SAE Brasil 2015, a maior velocidade atingida foi $13,8 \mathrm{~m} / \mathrm{s}(49,7 \mathrm{~km} / \mathrm{h})$, enquanto que a velocidade máxima teórica de um veículo Baja SAE é estipulada em 17,88 m/s (64,37 km/h) (REEDY, 2012). A partir desses dados, a velocidade do fluxo de ar foi estipulada na média desses dois valores: $16 \mathrm{~m} / \mathrm{s}(57,6 \mathrm{~km} / \mathrm{h})$. As demais condições determinadas para os testes foram as seguintes:

- Pressão estática: $101.325 \mathrm{~Pa}$

- Temperatura: $293,2 \mathrm{~K}\left(20^{\circ} \mathrm{C}\right)$

- Velocidade do escoamento no eixo longitudinal: $16 \mathrm{~m} / \mathrm{s}$

- Tipo de escoamento: laminar e turbulento

- Fluido considerado: ar com umidade zero.

\subsection{Carenagem traseira}

A carenagem traseira visa a diminuir o arrasto gerado pela carroceria do veículo e, dada a intenção de não se modificar o projeto original, optou-se 
por se concentrar na parte traseira, com a elaboração de um defletor no estilo kammback, solução bastante comum na indústria automobilística.

Nos anos 1930 já era de amplo conhecimento que a forma de menor resistência aerodinâmica em fluxo livre seria aquela que se aproximasse de uma gota; logo, para se minimizar o arrasto aerodinâmico, um veículo deveria ter uma traseira em forma de rampa descente em formato de cunha. Em 1938, o professor alemão Wunibald Kamm descobriu que, cortando abruptamente a traseira de um formato assim projetado, conseguia-se a maior parte dos benefícios desta forma sem os problemas de tamanho resultantes. 0 fluxo de ar, uma vez que tenha começado a seguir o perfil de cauda em formato de gota, tende a continuar seguindo este formato, mesmo que a ponta não esteja presente. Logo após o corte abrupto, cria-se um cone de ar turbulento no formato aproximado do restante do formato de gota, de forma que o fluxo segue, praticamente sem perturbações, ao seu redor. A esse fenômeno deu-se o nome de Efeito Kamm (TAYLOR, 1981) e ao estilo de traseira projetado com base nele, convencionou-se chamar de kammback.

Quando não é possível a adoção de uma traseira tipo kammback, por motivos estilísticos ou em veículos em que é necessário um ângulo muito acentuado de traseira, como peruas, hatchbacks e utilitários esportivos, podese adotar um defletor traseiro que agirá mimetizando um kammback, direcionando o fluxo de ar.

A carenagem traseira foi desenvolvida seguindo esses princípios, iniciando-se logo após a parede corta-fogo do veículo e integrando-se com a carenagem superior já presente no modelo utilizado como base. Alguns dos modelos testados durante a fase de desenvolvimento podem ser vistos na Figura 4.

Figura 4: Alguns dos modelos de carenagem traseira concebidas e testados.
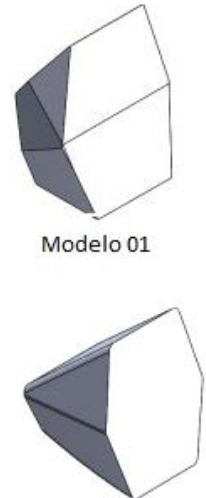

Modelo 05

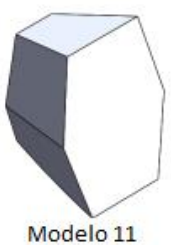

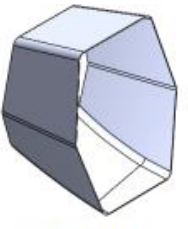

Modelo 02

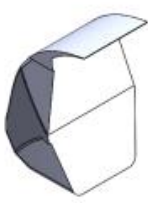

Modelo 06

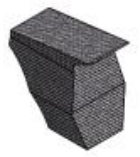

Modelo 26

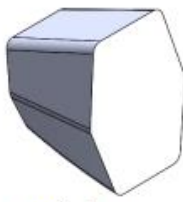

Modelo 03

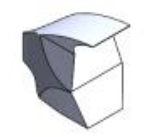

Modelo 07

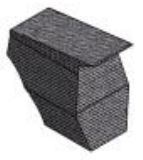

Modelo 30

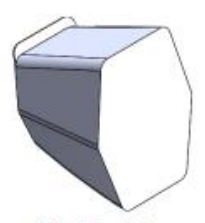

Modelo 04

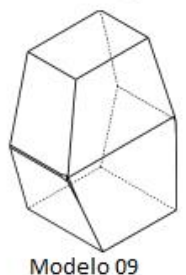

Modelo 09

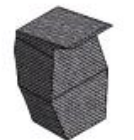

Modelo 31

Fonte: Elaborada pelos autores. 


\section{Resultados}

Os resultados das análises realizadas em software para análise de dinâmica dos fluidos computacional (CFD), considerando a aplicação de carenagens sobre os pneus e a adoção de carenagem traseira na forma de um defletor, são descritos nesta seção.

\subsection{Carenagem sobre os pneus}

A partir dos testes iniciais com as carenagens derivadas diretamente dos perfis aerodinâmicos, ao contrário do que se poderia esperar, alguns modelos de fato pioraram o desempenho do conjunto roda/pneu isolado, especialmente devido ao aumento da força tangente, decorrente da maior superfície interagindo com fluxo e do aumento da área frontal do conjunto carenagem/roda/pneu em relação à área frontal apenas do pneu com a roda. Isso pode ser atribuído ao fato de que algumas carenagens precisarem ter dimensões expressivamente maiores do que outras, para acomodar em seu interior o conjunto roda/pneu mantendo-se fiéis ao perfil gerador.

Destes testes, conclui-se que o perfil mais adequado é o Griffth 30\%. Apesar de este perfil ter sido concebido para usar o controle do escoamento turbulento através da sucção de parte deste escoamento, o uso desta geometria se mostrou bastante eficiente para aplicações caracterizadas pelo baixo número de Reynolds e a necessidade de uma grande espessura relativa (RICHARDS, 1945).

Com base nos resultados, várias carenagens foram elaboradas, modificadas e testadas de maneira empírica, com a formulação de várias alternativas e a verificação de qual fornecia um melhor desempenho. Em linhas gerais, o refinamento do projeto seguiu os seguintes passos: (a) Modificações no perfil mais promissor com base nos resultados de CFD obtidos; (b) Combinação entre dois perfis, um ditando a forma na vista lateral e outro na vista superior; (c) Refinamentos menores das formas (ex. corte de excessos, arredondamentos e outras pequenas modificações).

Adicionalmente, em veículos convencionais, quanto maior o volume do espaço entre o arco do para-lama e o pneu, maior será o arrasto. (THIVOLLE-CAZAT e GILLIÉRION, 2006) Logo, modificações na geometria da carenagem foram feitas de forma a minimizar o espaço entre as paredes internas da carenagem e o conjunto roda/pneu. 0 formato final da carenagem pode ser visualizado na Figura 5. 
Figura 5: Modelo final de carenagem aerodinâmica.

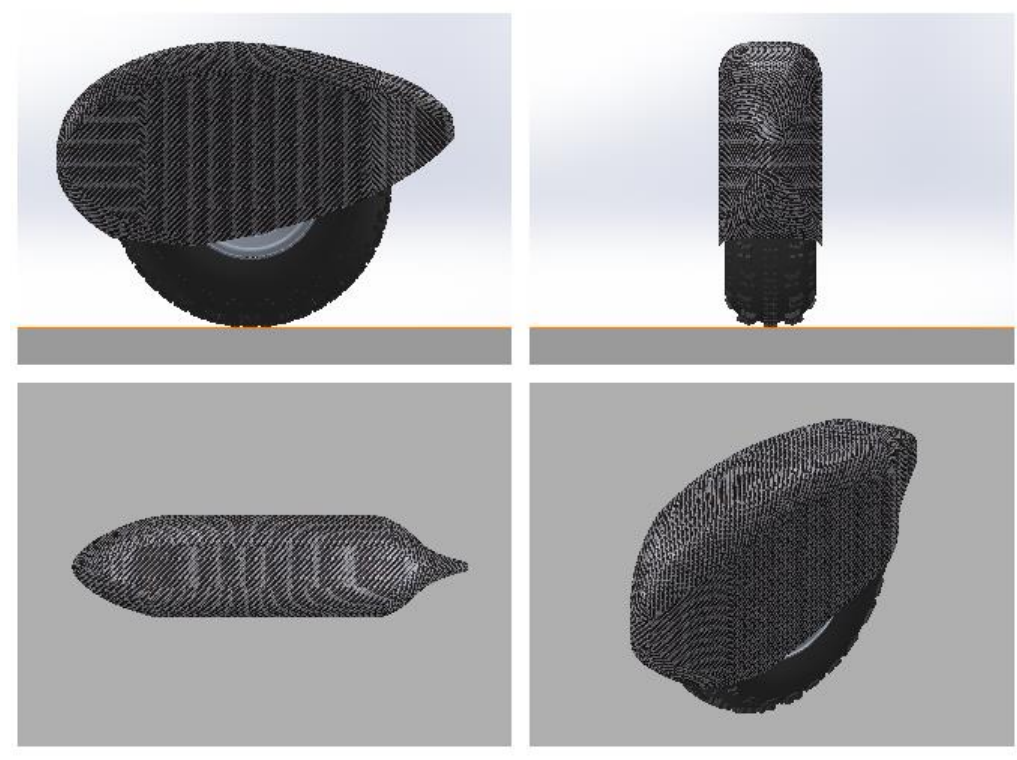

Fonte: Elaborada pelos autores.

\subsection{Carenagem traseira}

Devido ao fato de o fluxo aerodinâmico chegar à seção traseira do veículo bastante perturbado, a carenagem traseira deve ter dimensões significativamente maiores que um simples defletor usado em veículos de passeio produzidos em série para produzir algum resultado expressivo. Isso poderia ser contornado com a adaptação das peças da região frontal do veículo, porém isso iria contra as premissas deste estudo, ao modificar o projeto inicial do monoposto.

No final, a carenagem que se mostrou mais promissora baseou-se na adoção de um defletor parcial seguindo perpendicularmente nas laterais e com uma queda suave na parte superior. A peça conta com um defletor que cobre a parte superior e as laterais, sem limitações na parte posterior e na parte inferior. Obtido um formato inicial, algumas variações de comprimento e ângulo foram testadas. De acordo com Janusz (2009) obtêm-se os melhores resultados utilizando-se ângulos entre $5^{\circ}$ e $15^{\circ}$, assim deu-se prioridade para os valores neste intervalo.

Desse modo, o modelo final de carenagem ficou com uma inclinação descendente de $7^{\circ}, 110 \mathrm{~cm}$ de comprimento e laterais perpendiculares. As Figuras $6^{\mathrm{a}}$ e $6 \mathrm{~b}$ ilustram a adaptação de todos os elementos aerodinâmicos desenvolvidos no veículo. 
Figura 6a: Vistas frontal, lateral, superior e perspectiva isométrica do veículo Baja SAE em sua configuração inicial (esquerda).

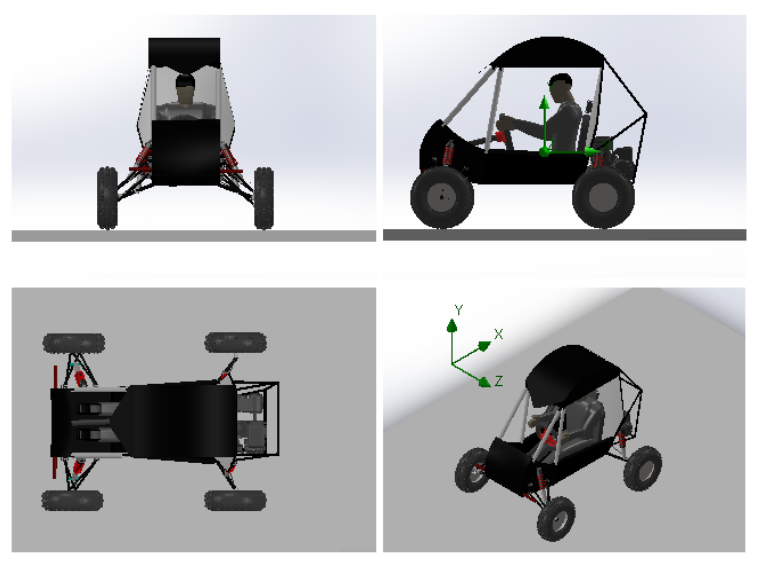

Fonte: Elaborada pelos autores.

Figura 6b: Vistas frontal, lateral, superior e perspectiva isométrica do veículo Baja SAE em sua configuração final (direita), com as carenagens sobre os pneus e com o defletor aerodinâmico traseiro.

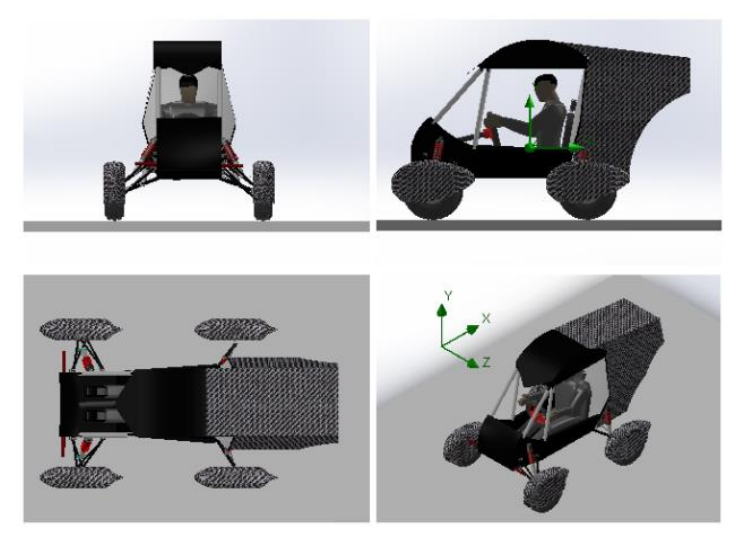

Fonte: Elaborada pelos autores.

\subsection{Determinação do coeficiente de arrasto}

Com os dados obtidos por CFD, foi possível o cálculo do Coeficiente de Arrasto do veículo em todas as configurações. Os resultados desses cálculos, juntamente com os dados de força aerodinâmica e os percentuais de redução obtidos estão condensados na Tabela 1:

Tabela 1: Resultados consolidados do desempenho do veículo Baja SAE simulado¹.

\begin{tabular}{|c|c|c|c|c|c|c|}
\hline \multirow{2}{*}{ Descrição } & \multicolumn{3}{|c|}{ Força Aerodinâmica (N) } & \multirow{2}{*}{$\begin{array}{c}\text { Red-1 } \\
(\%)\end{array}$} & \multirow{2}{*}{$\mathbf{C}_{\mathrm{d}}$} & \multirow{2}{*}{$\begin{array}{c}\text { Red-2 } \\
(\%)\end{array}$} \\
\hline & Fricção & Normal & Total & & & \\
\hline
\end{tabular}

\footnotetext{
${ }^{1}$ A coluna "Red-1" refere-se à redução percentual da força aerodinâmica total no eixo longitudinal, " $\mathrm{C}_{d}$ " refere-se ao coeficiente de arrasto do veículo em cada configuração e "Red-2" refere-se à redução do $\mathrm{Cd}$ para cada configuração em relação ao modelo de referência. Dados da força aerodinâmica apenas no eixo longitudinal.
} 


\begin{tabular}{|l|c|c|c|c|c|c|}
\hline Baja SAE sem carenagens & 1,41 & 136,13 & 137,54 & -- & 0,72 & -- \\
\hline $\begin{array}{l}\text { Baja SAE com carenagens nos } \\
\text { pneus }\end{array}$ & 1,84 & 120,73 & 122,57 & 10,9 & 0,63 & 11,7 \\
\hline Baja SAE com defletor traseiro & 2,51 & 126,47 & 123,96 & 8,1 & 0,65 & 9,8 \\
\hline Baja SAE com carenagens e defletor & 2,78 & 106,63 & 109,41 & 20,5 & 0,57 & 21,2 \\
\hline
\end{tabular}

\section{Discussão e considerações finais}

Ao final do desenvolvimento do pacote aerodinâmico e com o ensaio por CFD das peças obtidas, podem-se analisar os resultados gerais obtidos, compreender melhor os efeitos das carenagens no escoamento aerodinâmico e verificar se o emprego das peças é capaz de prover uma vantagem significativa perante o modelo inicial.

Observando o fluxo sobre o Baja (Figura 7), nota-se que, no veículo sem modificações, há uma zona de baixa pressão que se forma na parte traseira da carenagem e também é possível visualizar a turbulência que se forma logo atrás da parede corta-fogo do veículo, de forma que parte do fluxo é defletido e muda de direção antes de deixar o veículo, aumentando o arrasto. Quando as carenagens são adicionadas, percebe-se que a zona de baixa pressão sobre o veículo diminui e que, na parte traseira, há agora a formação de um cone de ar turbulento ao redor do qual o escoamento segue praticamente sem sofrer perturbações como prevê o Efeito Kamm.

De uma forma geral, percebe-se que toda a zona de baixa pressão na parte traseira do veículo (majoritariamente em verde na imagem) é reduzida com a adição do defletor. Analisando o fluxo no plano que corta as rodas e pneus do veículo (Figura 8), pode-se observar como as carenagens adotadas reduzem o arrasto. Primeiramente, há uma diminuição da zona de alta pressão (em vermelho e laranja) na frente das rodas dianteiras, seguido da diminuição da zona de baixa pressão existente logo após as rodas dianteiras e traseiras. 
Figura 7: Fluxo aerodinâmico ao redor do Baja SAE. Corte lateral centralizado.
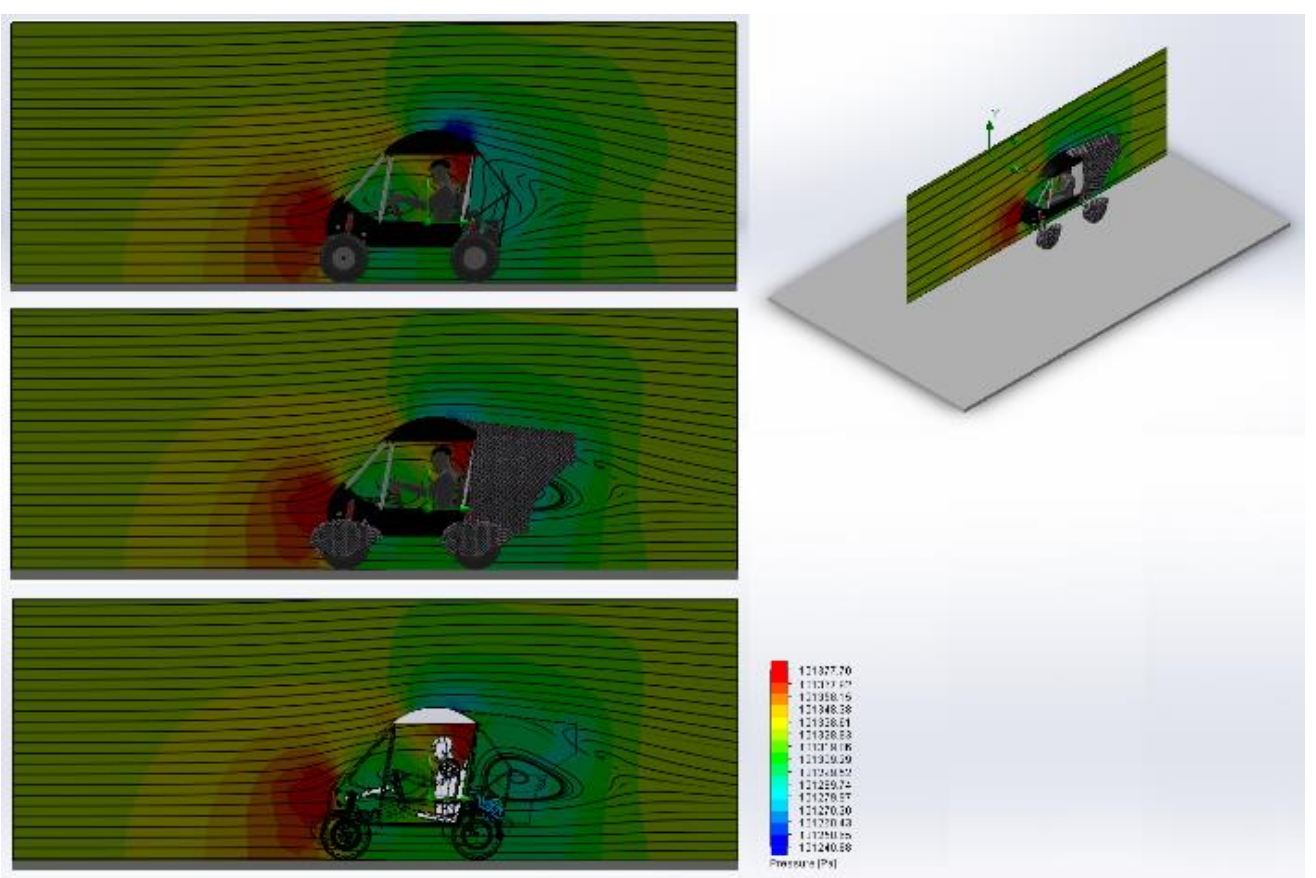

Fonte: Elaborada pelos autores.

Figura 8: Fluxo aerodinâmico ao redor do Baja SAE. Corte horizontal na altura dos pneus.
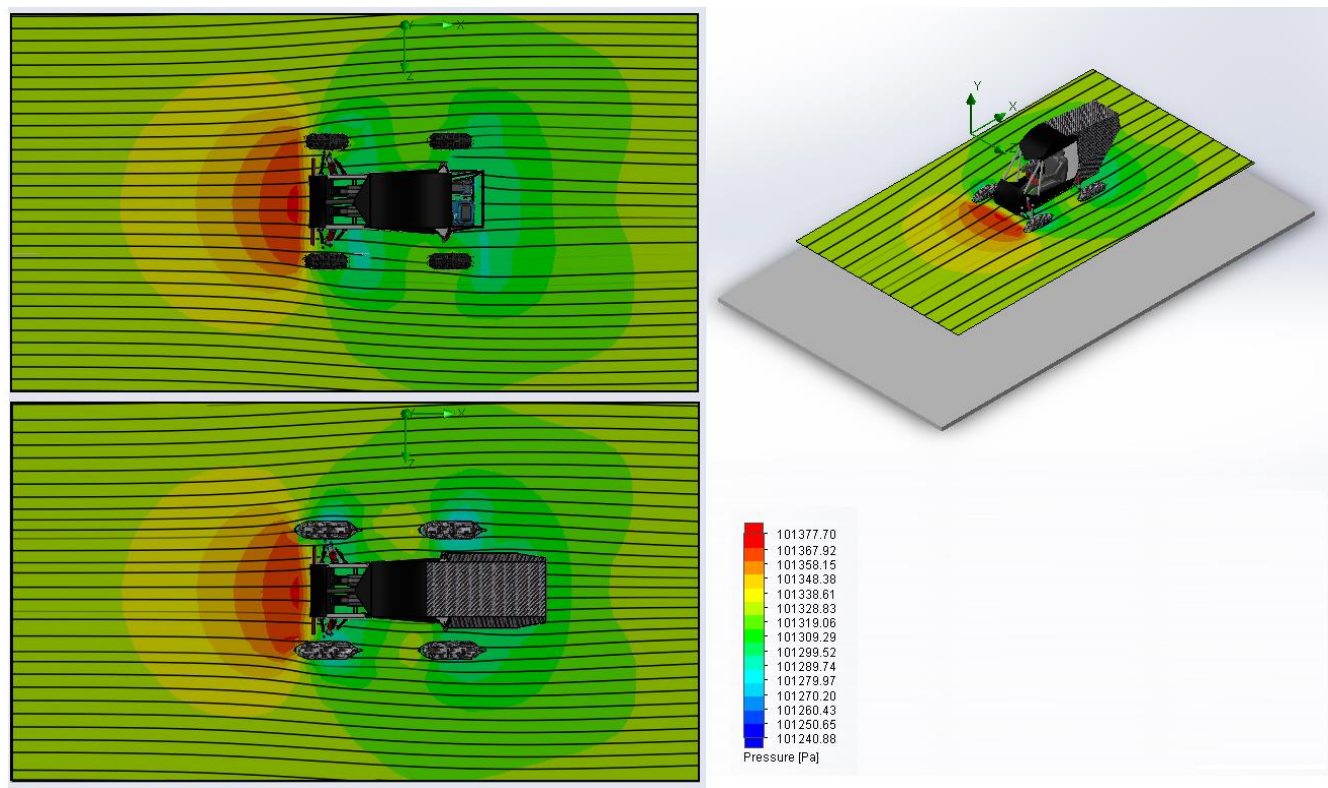

Fonte: Elaborada pelo autor

Analisando o escoamento aerodinâmico de cima, através dos cortes horizontais (Figuras 8 e 9), pode-se verificar claramente a diminuição da zona de alta pressão na parte dianteira do veículo e a diminuição das zonas de baixa pressão na traseira e nas regiões imediatamente atrás das rodas. Também se 
pode observar através das linhas de corrente como o fluxo se comporta por conta da presença do defletor traseiro. Com a presença da peça o escoamento aerodinâmico passa a se comportar de maneira mais fluida, passando ao lado do veículo sem turbilhonar atrás da parede corta-fogo.

Após a análise dos resultados obtidos e do cálculo do Coeficiente de Arrasto do veículo em todas as configurações, conclui-se que a adoção de carenagens aerodinâmicas tem potencial de prover um incremento significativo no desempenho dos veículos tipo Baja SAE.

Figura 9: Fluxo aerodinâmico ao redor do Baja SAE. Corte horizontal na altura média do defletor aerodinâmico traseiro.

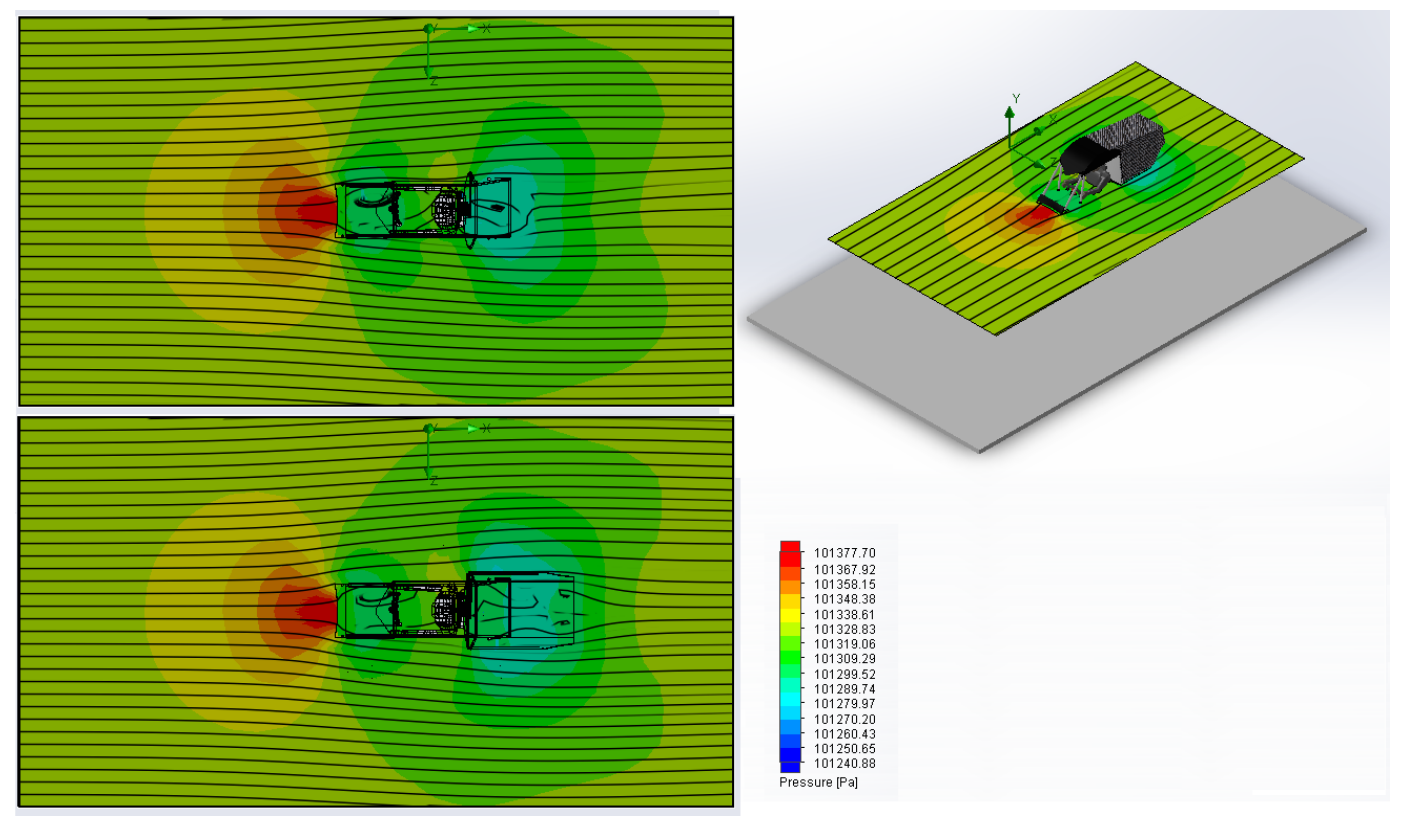

Fonte: Elaborada pelo autor

\section{REFERÊNCIAS BIBLIOGRÁFICAS}

ASSOCIAÇÃO BRASILEIRA DE NORMAS TÉCNICAS. NBR 15971-4: aeronáutica

- vocabulário - parte 4: propulsão aeronáutica. Rio de Janeiro, 2011.

JANUSZ, P. Podstawy Aerodynamiki Pojazdów. 1. ed. Varsóvia: Wydawnictwa Komunikacji i Lacznosci - WKL, 2009.

REEDY, C. Absolute top speed of competition ready car. [BAJA SAE Online

Forum] Disponível em: <http://forums.bajasae.net/forum/absolute-top- 
speed-of-competition-ready-car_topic1037.html> Acesso em 28 de agosto de 2017.

RICHARDS, E. J.; WALKER, W. S.; TAYLOR, C. R. Wind-tunnel tests on a 30 per cent suction wing. Ministry of Supply - Aeronautical Research Council Reports and Memoranda - Reports and Memoranda № 2149, 1945.

SAE BRASIL. Baja SAE Brasil. Disponível em: <http://portal.saebrasil.org.br /programas-estudantis/baja-sae-brasil>. Acesso em 10 de setembro de 2017. . Resultados 21ํㅡ Competição Baja SAE BRASIL - PETROBRAS. Disponível em:

<http://portal.saebrasil.org.br/Portals/0/PE/Pontua\%C3\%A7\%C3\%A3o\%2 0Baja

\%202015\%20-\%20Pontua\%C3\%A7\%C3\%A3o\%20Final.pdf>. Acesso em 10 de outubro de 2017.

SILVA, A. P. C.; VIEIRA, P. H., TAVARES, T. Proposta de otimização estrutural do veículo Baja SAE. 2016. Trabalho de Conclusão de Curso (Tecnologia em Mecânica Automotiva) - Faculdade de Tecnologia de Santo André, Santo André - SP, 2016.

TAYLOR, R. Searching for the perfect .10. Popular Mechanics, Set. 1981.

THIVOLLE-CAZAT, E; GILLIÉRION, P. Flow analysis around a rotating wheel. 13th International Symposium on Applications of Laser Techniques to Fluid Mechanics. Lisboa, Portugal, jun. 2006.

\section{AGRADECIMENTOS}

Agradecimentos aos estudantes da UFABC que participaram da equipe BAJA UFABC ao longos dos últimos anos e que alguma maneira colaboraram para que esse trabalho fosse feito. 